\title{
Ovicidal Efficacy of Metarhizium anisopliae (Hypocreales: Clavicipitaceae) towards Rhipicephalus sanguineus (Acari: Ixodidae) Eggs
}

\author{
Nur Izzati, Z.A. ${ }^{1}$, Syazwan, S.A. ${ }^{2,3}$, Lee, S.H. ${ }^{4}$, Ruhil Hayati, H. ${ }^{1}$, Peng, T.L. ${ }^{{ }^{*}}$ \\ ${ }^{1}$ Faculty of Veterinary Medicine, Universiti Malaysia Kelantan, Locked bag 36, Pengkalan Chepa, 16100 Kota Bharu, Kelantan, Malaysia \\ ${ }^{2}$ Mycology and Pathology Laboratory, Forest Health and Conservation Programme, Forest Research Institute Malaysia, 52109 Kepong, Selangor, \\ Malaysia \\ ${ }^{3}$ Forest Biotechnology Laboratory, Department of Forest Management, Faculty of Forestry, Universiti Putra Malaysia, 43400 UPM Serdang, Selangor, \\ Malaysia \\ ${ }^{4}$ Institute of Tropical Forestry and Forest Products, Universiti Putra Malaysia, 43400 UPM Serdang, Selangor, Malaysia \\ *Corresponding authors: li.peng@umk.edu.my; lee_seng@upm.edu.my
}

\section{ARTICLE HISTORY}

Received: 17 December 2019 Revised: 28 August 2020 Accepted: 1 September 2020 Published: 25 March 2021

\begin{abstract}
Rhipicephalus sanguineus, commonly known as brown dog tick is a widespread species with considerable public health and economic importance. Tremendous efforts were performed to control the tick populations with the concern of resistance build-up and environmental issues. Alternative towards microbial control thus emerged as one option to reduce tick populations. In this study, the ovicidal efficacy of a native isolate entomopathogenic hyphomycetes fungi, Metarhizium anisopliae strain HSAH5 was evaluated against eggs of $R$. sanguineus. Spray applications with three different conidial concentrations of $10^{5}, 10^{6}$ and $10^{7}$ conidia $\mathrm{mL}^{-1} ; 40 \mathrm{ppm}$ of Flumethrin and a negative control. The $M$. anisopliae strain was found highly virulent to $R$. sanguineus eggs by reducing the hatching percentages to $\approx 30 \%$ compared with $8.9 \%$ in Flumethrin eggs. The result showed a significantly higher mortality in $M$. anisopliae group than those of the control groups $(F=42.08, d f=32, P<0.001)$ at 30 days post-infection. However, there are no significant differences within the M. anisopliae group, in which the mortality between different conidial concentrations is almost the same. The estimated $\mathrm{LC}_{50}$ of $M$. anisopliae against eggs of $R$. sanguineus is $1.36 \times 10^{3}$ conidia $\mathrm{ml}^{-1}$. Thus, these results suggest $M$. anisopliae strain HSAH5 could be a potential biocontrol agent of $R$. sanguineus in the integrated approach to managing ticks in the residential landscape by targeting on the eggs.
\end{abstract}

Keywords: Entomopathogenic Fungus; LC 50 ; Native strain; Tick eggs; Biological control.

\section{INTRODUCTION}

Rhipicephalus sanguineus (Arachnida: Ixodidae) or commonly known as brown dog tick is the most widespread cosmopolitan ticks in the world with great significance in the veterinary industry and human health. This tick is the vector of many important pathogens that caused high mortality and morbidity with considerable economic impacts (DantasTorres et al., 2012). Rhipicephalus sanguineus has three nonparasitic off-host periods which are relatively long compared to the on-host periods. Engorged females will oviposit clusters of large numbers of eggs in protected locations which are dark, humid and with moderate temperature; these eggs are difficult to eliminate, and the survival of the offspring eventually maintain substantial tick populations (Dantas-Torres, 2008).

As with many other major pests, the control of $R$. sanguineus is usually attempted with chemicals control, although this approach may present disadvantages such as the development of resistance, human and animal toxicity and environmental pollution. Therefore, a new interest towards biological control of ticks had been developed, particularly on entomopathogenic fungi (Fernandes \& Bittencourt, 2008). Although a few entomopathogenic fungi are reported to be effective towards several tick species, the susceptibility of ticks to fungi might vary according to tick species and population as well as to fungal strain (Fernandes et al., 2012; Perinotto et al., 2012).

As the egg masses of ticks are often being laid in such conditions which are also suited for the development of entomopathogenic fungi, $R$. sanguineus eggs could be the key targets for controlling tick populations with mycoacaricides. Infectious conidia can either get into contact with tick eggs indirectly on substrates which are previously treated with the fungus or treated topically (directly) with conidia. Whereas fungal activity against $R$. sanguineus eggs, larvae, nymphs, and adults is well established (Dantas-Torres, 2008; Fernandes \& Bittencourt, 2008; Gindin et al., 2009), the native 
strains have been shown to be more virulent (Pajar et al., 2013). However, of the few studies available in the literature on the use of entomopathogenic fungi against $R$. sanguineus, none of the native strains of these fungi were tested against $R$. sanguineus. Therefore, the aim of this study was to investigate the in-vitro efficacy of a native strain of Metarhizium anisopliae (Ascomycota: Clavicipitaceae) towards eggs of $R$. sanguineus.

\section{MATERIALS AND METHODS}

\section{Tick Samples}

A total of 20 engorged female $R$. sanguineus collected from ticks infested dog in Kuala Lumpur, Perak and Kelantan were identified under a stereomicroscope using references from Abdullah et al. (2016) and Walker et al. (2014). These engorged females were surface sterilized by dipping in $0.1 \%$ sodium hypochlorite solutions to remove possible environmental fungi and bacteria and rinsed with sterile distilled water before placing in a sterile container with moist filter paper for oviposition. Tick specimens were maintained under controlled conditions of temperature $\left(27 \pm 2^{\circ} \mathrm{C}\right)$, relative humidity ( $\mathrm{RH} 80 \pm 5 \%$ ) and photoperiod ( $12 \mathrm{~h}$ light, $12 \mathrm{~h}$ dark) to produce eggs.

\section{Metarhizium anisopliae Origin and Suspension Preparation}

A pure culture of Metarhizium anisopliae strain HSAH5 was obtained from Universiti Putra Malaysia (UPM). This strain was isolated from soil in Ayer Hitam Forest Reserve, Puchong, Selangor, Malaysia. It was then identified and archived in Institute of Bioscience, UPM (UPMC869) and was deposited in NCBI GenBank (Accession No.: KX279867).

The fungus was sub-cultured on sabourad dextrose agar (SDA) agar and passaged on sterilized Tenebrio molitor larvae before being maintained on SDA and kept at $4^{\circ} \mathrm{C}$ for further use. The conidial suspensions of $M$. anisopliae were prepared by growing the fungus on ten Petri dishes containing SDA for 2 weeks at $28 \pm 2^{\circ} \mathrm{C}$. Conidia were harvested by washing the Petri dishes with sterile distilled water containing $0.2 \%$ Tween 80 and filtered through a sterile filter paper to eliminate agar and mycelia. The concentrations of the conidia suspension were then determined by using the Neubauer chamber and adjusted to $10^{5}, 10^{6}$ and $10^{7}$ conidia $\mathrm{mL}^{-1}$ using dilution method. The negative control was a sterile $0.2 \%$ Tween 80 solution, while the positive control was a dilution of Flumethrin (Bayticol 6\% E.C.) with distilled water into $40 \mathrm{ppm}$.

\section{Laboratory Bioassay}

Eggs laid during the first 4 days were collected for the bioassay. The eggs from each female tick were considered as a replicate and were randomly divided into five groups of equivalent number by counting them under a dissecting microscope and transferring them onto a sterile container with moist filter paper using a decontaminated fine camel brush (size 00). Egg clumps were first separated by agitating shortly with distilled water before the counting and transferring procedures to reduce the handling times. Filter papers in the plates were moisten from time to time to avoid desiccation. Plates were covered immediately after each transfer to reduce desiccation and avoid contamination as well.

A total of 10 replicates comprising of 456 eggs for each groups were used in this bioassay. The bioassay was composed of five Petri dishes for two were the control groups (positive \& negative control) and three as the treatment groups ( 3 different conidial concentrations). The eggs were sprayed with $0.5 \mathrm{ml}$ of the treatment or control solution by using a cosmetic hand sprayer. The Petri dishes were sealed with parafilm and maintained under controlled conditions (see above). Eggs were examined under microscope and were considered hatched if a part of the larvae were seen out from the eggs shell (although it was not fully detached from the egg shell). The hatching rate was recorded every five days by observing the eggs under a stereomicroscope. The bioassay was terminated after 30 days of treatment.

\section{Data Analysis}

The results were reported as mean values in percentage. The eggs mortality of each treatment was indicated by the number of unhatched eggs after treatment and adjusted by using Sun-Shepard's formula (Püntener, 1981) prior analysis. The data were analysed using one-way analysis of variance (ANOVA) at $5 \%$ level of significance $(p \leq 0.05)$. The lethal concentration at $50 \%$ and $90 \%\left(\mathrm{LC}_{50}\right.$ and $\left.\mathrm{LC}_{90}\right)$ were calculated using probit analysis. All statistical analyses were conducted using SAS $^{\circledR}$ Studio release 3.8 (SAS Institute, Inc., Cary, NC, USA). Meanwhile, for dose-response ( $\mathrm{LC}_{50}$ and $\mathrm{LC}_{90}$ ) graph was generated and visualized using Prism 7 for MacOS $X$ ver. 7.0a (GraphPad Software, La Jolla, CA, USA).

\section{RESULTS AND DISCUSSION}

The in-vitro effect of $M$. anisopliae on eggs of $R$. sanguineus is shown in Figure 1. White fungal mycelium started to emerge and sporulate on the surface of the eggs of $R$. sanguineus started on day 3 post-treatment with the highest number of mycelia growth $(42.7 \%)$ at $10^{7}$ conidia $\mathrm{mL}^{-1}$, followed by $10^{6}$ conidia $\mathrm{mL}^{-1}(0.8 \%)$ and $10^{5}$ conidia $\mathrm{mL}^{-1}(0.4 \%)$ (Figure 1$)$. The formation of conidia began at day five post-treatment with the highest number of sporulation $(84.6 \%)$ at $10^{7}$ conidia $\mathrm{mL}^{-1}$, followed by $10^{6}$ conidia $\mathrm{mL}^{-1}(30 \%)$ and $10^{5}$ conidia $\mathrm{mL}^{-1}$ $(10 \%)$ (Figure 1). Larvae from both controls and treatment group hatched at day 13 post-treatment; in which the larvae from the treatment group $\left(10^{5}\right.$ conidia $\left.\mathrm{mL}^{-1}\right)$ and negative control were relatively strong and active compared to the positive control. The larvae from the positive control were weak as compared to the negative control in which larvae were not completely detached from the egg shell or limb were not fully extended, inactive whereby the movement were slow and die soon after hatching.

Eggs that unable to hatch were considered die and indicated eggs mortality. The treatment groups have shown that this $M$. anisopliae strain was highly virulent to $R$. sanguineus eggs and able to cause mortality up to $29.57-30.22 \%$ compared with only $8.97 \%$ of mortality in Flumethrin. The result showed a significantly higher mortality in treament groups than those of the control groups $(F=42.08, d f=32, P<0.001)$ after 30 days of treatment. However, there are no significant differences within $M$. anisopliae group and within the control group, in which the mortality between different conidial concentrations and between positive and negative control are almost the same (Table 1). The estimated LC $_{50}$ of $M$. anisopliae strain HSAH5 against $R$. sanguineus eggs was $1.36 \times 10^{3}$ conidia $\mathrm{mL}^{-1}$ while the $\mathrm{LC}_{90}$ value was $1.47 \times 10^{4}$ conidia $\mathrm{mL}^{-1}$ (Figure 2).

The present study shows, for the first time, that a native strain of $M$. anisopliae was found highly virulent towards $R$. sanguineus eggs. Metarhizium anisopliae has long been studied on its efficacy towards different species of soft and hard ticks (Gindin et al., 2009; Ren et al., 2016; FernandezSalas et al., 2017; Fischhoff et al., 2017; Prado-Rebolledo et al., 


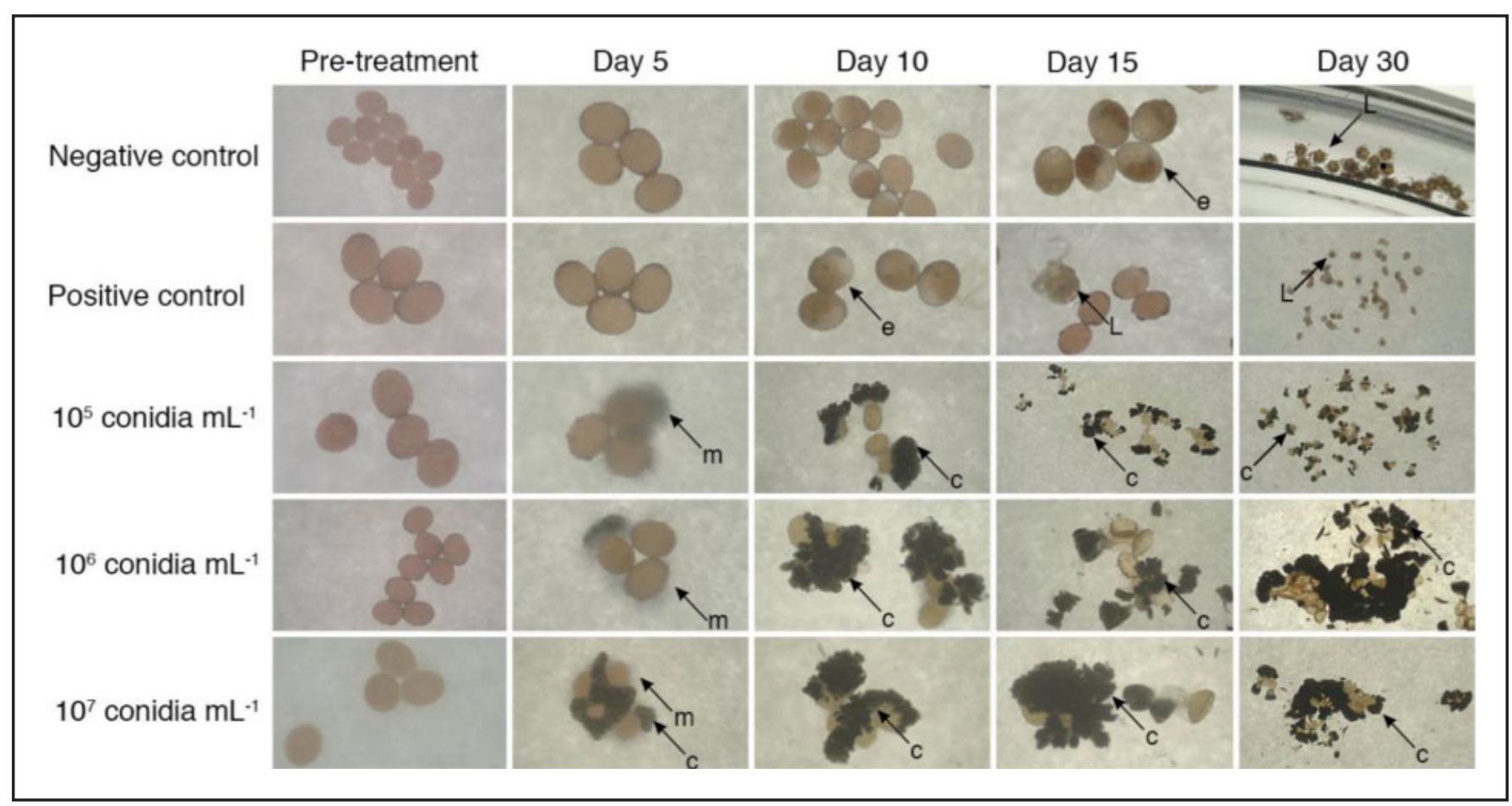

Figure 1. The in-vitro effect of different treatments on eggs of $R$. sanguineus at different period of time.

*Note: $\mathrm{c}=$ conidia; $\mathrm{m}=$ mycelia, $\mathrm{L}=$ larvae; $\mathrm{e}=$ embryo.

Table 1. Mortality of $R$. sanguineus eggs treated with different $M$. anisopliae concentration and positive control

\begin{tabular}{lc}
\hline Treatment & Mortality $(\% \pm \mathrm{SD})$ \\
\hline Positive control (Flumethrin, $40 \mathrm{ppm})$ & $8.97 \pm 2.16 \mathrm{a}$ \\
$10^{5}$ conidia $\mathrm{mL}^{-1}$ & $29.57 \pm 4.82 \mathrm{~b}$ \\
$10^{6}$ conidia $\mathrm{mL}^{-1}$ & $30.22 \pm 4.90 \mathrm{~b}$ \\
$10^{7}$ conidia $\mathrm{mL}^{-1}$ & $30.22 \pm 4.90 \mathrm{~b}$ \\
\hline
\end{tabular}

${ }^{a b}$ Means followed by the same letter did not differ significantly $(p<0.05$, Tukey HSD Test $=6.45$ ).

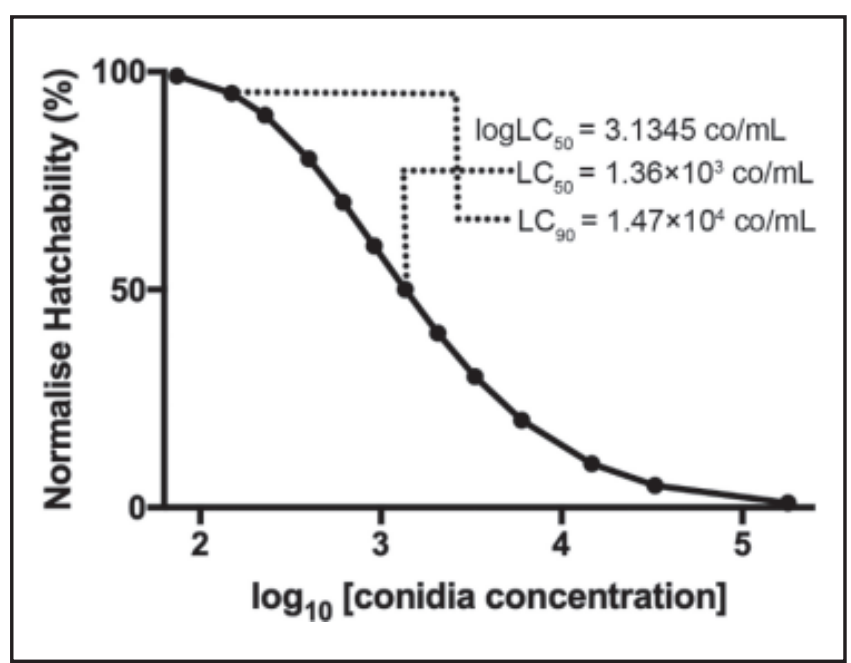

Figure 2. Dose-response curve of $R$. sanguineus eggs hatchability after treated with $M$. anisopliae conidial suspension.
2017). However, the effectiveness of fungus are subjected to many factors, one of the most important factors is the isolates of fungus. Indigenous isolates that have been adapted to local conditions are often found to be more effective in controlling the pest as they are more tolerant to the abiotic factors around (Pajar et al., 2013). Indeed, M. anisopliae strain HSAH5 containing $10^{6}$ and $10^{7}$ conidia $\mathrm{mL}^{-1}$ were able to cause $100 \%$ mortality on local $R$. sanguineus eggs. This result is also in agreement with the findings by Gindin et al. (2009) where the study shows that $R$. sanguineus eggs are more susceptible to $M$. anisopliae compared to $R$. annulatus.

Surprisingly, the mortality caused by flumethrin exposure (positive control) was only $8.97 \%$, which was subsided compared to eggs treated with $M$. anisopliae spore suspension. This result was contradicted by Haque et al. (2014) in which this commonly used acaricide are able to caused complete inhibition on Rhipicephalus (Boophilus) microplus eggs from hatching. Nevertheless, the difference may be deduced from the different species that have been tested on, as the susceptibility of different ticks species and even population may vary (Dantas-Torres, 2008). It might also due to the probability of acaricide resistance development of local tick population (Bandara et al., 2017). The bigger deviation on the results of mortality between the replicates of positive control indicates acaricidal resistance build-up might have happened on certain population groups of $R$. sanguineus as the ticks which were collected from different locations in Malaysia.

The ovicidal efficacy of $M$. anisopliae is dose-dependent, whereby the highest concentration used in this study having a better coverage and rapid mycelia growth following by sporulation. This was supported by Adames et al. (2011) that shows higher eggs mortality (55\%) was achieved when exposed to $10^{8}$ conidia $\mathrm{mL}^{-1}$ compared to the only $7 \%$ 
when $10^{4}$ conidia $\mathrm{mL}^{-1}$ was being applied. The difference might due to a higher conidial concentration increased the distribution of conidia on all eggs. This eventually enabled mycelium and conidia developed simultaneously on a high proportion of eggs and thus reduced the time of fungal development and increased the overall ovicidal activity (Luz et al., 2016). The $\mathrm{LC}_{50}$ and $\mathrm{LC}_{90}$ of this study corresponded with Luz et al. (2016), however, zero larvae eclosed from clustered eggs treated were not achieved in this study with the concentration of $10^{5}$ conidia $\mathrm{mL}^{-1}$. The reason might be due to uneven distribution of conidia on the eggs cluster when the lower concentration was used; it was then reduced the efficiency of the conidia.

\section{CONCLUSION}

Metarhizium anisopliae is one of the promising candidates of biocontrol even for the tick. In general, ticks controlling can either be done on or off hosts. The latter provides a means to reduce new infestation by killing off the moulting stages of ticks and more importantly the eggs. These results suggest that the native strain of $M$. anisopliae can be a potential biocontrol agent for reducing tick populations by killing off the egg masses of economically important ticks. Advantage such as sustainability of the fungus in controlling the ticks population can also be achieved when the application sites in which the ticks and egg masses present are also favourable for fungal development and persist for many months.

\section{ACKNOWLEDGEMENTS}

The author wish to acknowlegde the Faculty of Veterinary Medicine, Universiti Malaysia Kelantan for providing incentive to conduct the Final Year Project for undergraduate student.

\section{Conflict of interest}

The authors declare that they have no conflict of interest.

\section{REFERENCES}

Abdullah, S., Helps, C., Tasker, S., Newbury, H. \& Wall, R. (2016). Ticks infesting domestic dogs in the UK: a large-scale surveillance programme. Parasites \& Vectors 9: 391. https://doi.org/10.1186/s13071-016-1673-4

Adames, M., Fernández-Ruvalcaba, M., Peña-Chora, G. \& Hernández-Velázquez, V.M. (2011). Effects of passages through a suitable host of the fungus, Metarhizium anisopliae, on the virulence of acaricide-susceptible and resistant strains of the tick, Rhipicephalus microplus. Journal of Insect Science 11: 21. https://doi.org/10.1673/031.011.0121

Bandara, J., Dissanayake, D.M.A.P., de Silva, P. \& Parakrama Karunaratne, S.H.P. (2017). First report on emerging resistance to Amitraz and Flumethrin in Rhipicephalus sanguineus (brown dog tick) at police kennels, Kandy, Sri Lanka: a case study. In: Proceedings of Sri Lanka-Taiwan Joint Symposium on Advances in Entomological Research, 20 Jan 2017, Postgraduate Institute of Science, University of Peradeniya, Sri Lanka.

Dantas-Torres, F. (2008). The brown dog tick, Rhipicephalus sanguineus (Latreille, 1806) (Acari: Ixodidae): from taxonomy to control. Veterinary Parasitology 152: 173-185. https://doi. org/10.1016/j.vetpar.2007.12.030

Dantas-Torres, F., Chomel, B.B. \& Otranto, D. (2012). Ticks and tick-borne diseases: a One Health perspective. Trends in Parasitology 28: 437-446. https://doi.org/10.1016/j.pt. 2012.07.003
Fernandes, É.K.K. \& Bittencourt, V.R.E.P. (2008). Entomopathogenic fungi against South American tick species. Experimental and Applied Acarology 46: 71-93. https://doi. org/10.1007/s10493-008-9161-y

Fernandes, E.K., Bittencourt, V.R.E.P. \& Roberts, D.W. (2012). Perspectives on the potential of entomopathogenic fungi in biological control of ticks. Experimental Parasitology 130: 300-305. https://doi.org/10.1016/j.exppara.2011.11.004

Fernandez-Salas, A., Alonso-Diaz, M.A., Alonso-Morales, R.A., Lezama-Gutiérrez, R., Rodríguez-Rodríguez, J.C. \& Cervantes-Chávez, J.A. (2017). Acaricidal activity of Metarhizium anisopliae isolated from paddocks in the Mexican tropics against two populations of the cattle tick Rhipicephalus microplus. Medical and Veterinary Entomology 31: 36-43. https://doi.org/10.1111/mve.12203

Fischhoff, I.R., Keesing, F. \& Richard, S.O. (2017). The tick biocontrol agent Metarhiziumbrunneum ( $=M$. anisopliae) (strain F52) does not reduce non-target arthropods. PLOS One 12: e0187675. https://doi.org/10.1371/journal.pone. 0187675

Gindin, G., Ment, D., Rot, A., Glazer, I. \& Samish, M. (2009). Pathogenicity of Metarhizium anisopliae (Hypocreales: Clavicipitaceae) to tick eggs and the effect of egg cuticular lipids on conidia development. Journal of Medical Entomology 46: 531-538. https://doi.org/10.1603/033.046.0318

Luz, C., D'Alessandro, W.B., Rodrigues, J. \& Fernandes, E.K. (2016). Efficacy of water- and oil-in-water-formulated Metarhizium anisopliae in Rhipicephalus sanguineus eggs and eclosing larvae. Parasitology Research 115: 143-149. https://doi.org/10.1007/s00436-015-4729-z

Pajar, J.A.L., Derick, V.C., Nanette, H.N.S., Joey, G.T.M., Ma, R.S.B.M. \& Henry, I.R. (2013). Virulence of local Metarhizium spp. isolates against Tenebrio molitor (Linn): an initial comparison with non-native and commercially available strains. In: Proceedings of The Third International Congress on Interdisciplinary Research and Development, 30-31 May 2013, Muang Thong Thani, Bangkok, Thailand. pp. 55.1

Perinotto, W.M.S., Angelo, I.C., Golo, P.S., Quinelato, M.G., Camargo, M.G., Sa, F.A. \& Bittercourt, V.R. (2012). Susceptibility of different populations of ticks to entomopathogenic fungi. Experimental Parasitology 130: 257-260. https://doi.org/10.1016/j.exppara.2011.12.003

Prado-Rebolledo, O.F., Molina-Ochoa, J., Lezama-Gutierrez, R., Garcia-Marquez, L.J., Minchaca-Llerenas, Y.B., MoralesBarrera, E., Tellez, G., Hargis, B., Skoda, S.R. \& Foster J.E. (2017). Effect of Metarhizium anisopliae (Ascomycete), Cypermethrin, and D-Limonene, alone and combined, on larval mortality of Rhipicephalussanguineus (Acari: Ixodidae). Journal of Medical Entomology 54: 1323-1327. https://doi.org/10.1093/jme/tjx092

Püntener, W. (Ed.). (1981). Manual for field trials in plant protection. Ciba-Geigy.

Ren, Q., Chen, Z., Luo, J., Liu, G., Guan, G., Liu, Z., Liu, A., Li, Y., Niu, Q. \& Liu, J. (2016). Laboratory evaluation of Beauveria bassiana and Metarhizium anisopliae in the control of Haemaphysalis qinghaiensis in China. Experimental and Applied Acarology 69: 233-238. https://doi.org/10.1007/ s10493-016-0033-6

Walker, A.R., Bouattour, A., Camicas, J.L., Estrada-Peña, A., Horaf, I.G., Latif, A.A., Pegram, R.G. \& Preston, P.M. (2014). Ticks of domestic animals in Africa: a guide to identification of species. Edinburgh Scotland: Bioscience Reports. 